\title{
Exploration on Survival Status and Competency Level of Rural Kindergarten Job-transfer Teachers in Shaanxi Province
}

\author{
Jie Liu \\ Faculty of Pre-school Education, Shaanxi Xueqian Normal University, Xi'an, 710100, China
}

Keywords: Rural kindergarten in Shaanxi province; Job-transfer teachers; Competency level

\begin{abstract}
At the initial stage of taking work, the overall adaptation situation of rural kindergarten job-transfer teachers in Shaanxi province is under medium level; according to occupational adaptive capacity, it can be divided into occupational relation, occupational psychology, occupational skills, and occupational environment; in order to fundamentally change the adaptive level of rural kindergarten job-transfer teachers in Shaanxi province, it is required to start from job-transfer teachers' policy and working environment to strive to improve job-transfer teachers' comprehensive quality. Through analysis on survival status of rural kindergarten job-transfer teachers in Shaanxi province, this paper carries out relevant exploration on how to improve the competency level of rural kindergarten job-transfer teachers.
\end{abstract}

\section{Introduction}

Currently, the pre-school education has realized unprecedented development, the primary and secondary education shows a centralized trend, and the surplus teachers of primary and secondary schools start to transfer into kindergarten; the change is especially obvious in rural kindergarten job-transfer teachers. The domestic research on rural kindergarten job-transfer teachers have made certain results, but there still exists great improvement space; the old cultural knowledge, old age, and insufficient professional cultivation knowledge for children cause limited teaching level of kindergartens. Therefore, to select suitable primary school teachers for job transfer, adopt multiple ways to carry out employment training, and perfect later daily work incentive mechanism is of important significance.

\section{Analysis on survival status of rural kindergarten job-transfer teachers in Shaanxi province}

1). In recent years, due to adjustment and restraint of national family planning policy, the impact of late marriage and late childbirth is enhanced, the rural urbanization process is quickened, and the population mobility is also quickened; the imbalance gradually appears in urban and rural education, and the school-age children in rural area decreases year by year. The rural primary and secondary schools face serious challenges, and the previously matched faculty is superfluous. The problems such as insufficient pre-school education and teaching resource and weak faculty in rural area enhance the conflict in rural education. In November 2010, the State Council of the People's Republic of China issued Several Opinions on Development of Pre-school Education which clearly proposed to integrate rural education development status and adjust surplus education resource and also proposed that the surplus teachers of primary and middle schools could be transferred to the posts of pre-school education through training and verification. Therefore, it can be seen that this kind of faculty transferred from primary and middle schools to kindergartens must become the backbone force in rural kindergarten education and plays a key role in balancing the education problems occurred in urbanization process while China's pre-school education development enters into special period.

2). Currently, the rural kindergarten job-transfer teachers in Shaanxi province generally have low degree of education, with low professional counterpart rate and treatment, and high rate of staff resignation; although they have strong development motivation, they lack of systematic professional training, have insufficient professional knowledge, pay little attention to knowledge of basic subjects, 
and have relatively low teaching and research ability. In general, the training method is to go to the cities and towns with good development for empathic learning; the teachers lack of fixed development objective and the faculty is seriously insufficient. Therefore, as for the survival status of rural kindergarten job-transfer teachers in Shaanxi province, it is required to pay attention to the professional development demand of rural kindergarten teachers, strive to perfect relevant training system on the basis of improving teachers' self-awareness, and actively carry out kindergarten training. Many scholars have carried out discussion on rural kindergarten job-transfer teachers, which provides strong academic foundation for this paper. Under the support and guidance of national policies, no accurate definition is given to rural kindergarten job-transfer teachers in China, which will cause a barrier for development of China's rural children education and also cause imbalanced development of urban and rural education. Therefore, the author takes rural kindergarten job-transfer teachers in Shaanxi province as an example to carry out exploration on their professional development, survival status, and competency level, which is of important significance.

$3)$. In the key period of development of national compulsory education and pre-school education, the appearance of job-transfer teachers can help to mitigate the problem of insufficient faculty in school education, and the reasonable mobility can be realized between the teaching resource of primary schools and teaching resource of kindergartens; however, the current job-transfer teachers are generally of old age, it is hard for them to spend sufficient energy in operating kindergarten pupils' education, and it seems that there is a sign that they get rid of burden from primary schools to kindergartens. Besides, while those job-transfer teachers with qualification certificates and many years of experience face new groups, the inadaptation may happen for them. Before the job-transfer teachers officially take the work, the easy kindergarten training can't let those teachers deeply understand the change of teaching method caused by change of group, which finally causes great fall with teachers' expected value; the passive psychological attitude restrains teachers' enthusiasm in work. The job-transfer teachers without systematic kindergarten training have poor knowledge structure, and the primary school trend appears in kindergartens, which reduces the overall teaching quality of pre-school education on the contrary, and especially reduces the level of pre-school education development in rural kindergartens.

\section{Strategies for improving competency level of rural kindergarten job-transfer teachers in Shaanxi province}

Through consulting to relevant theoretical literature and data about job-transfer teachers, the author analyzes the survival status and competency level of rural kindergarten job-transfer teachers in Shaanxi province, makes a reflection on current problems of job-transfer teacher development, and combines with the author's personal teaching experience to propose following suggestions for the purpose of promoting rural kindergarten job-transfer teachers in Shaanxi province to obtain better development in professional ability.

\section{To select suitable job-transfer teachers}

Due to the specialty, there is fundamental difference between primary and secondary education and pre-school education; the specificity of educated objects determines different focuses of work, and different forms and contents. The teachers who never consider their difference or directly deny either of them shall be not included into the range of job-transfer personnel. The 4-year-old children's body is under rapid development stage, and they have strong perception on external things, thus the game-oriented teaching form is the fundamental starting point to carry out school education courses. In general, the teaching content shall be simple and easy language, society, science, art, and other subjects with wide involvement; the old teachers shall not directly engage in second-line kindergarten education activities after they exit from primary and middle schools, and the age of job-transfer teachers shall be controlled below 35 years old; the primary school teachers with qualifications or certificates of early children education have the priority to make transfer. 


\section{To carry out targeted and effective job-transfer training for job-transfer teachers}

Although the job-transfer teachers generally have mature teaching experience, their knowledge reserve for early children education is blank, and only the job-transfer teachers who have accepted systematic job-transfer training can be capable of the post of kindergarten teacher. The training items must be targeted and effective to early children education, and the sufficient time, strict inspection, and flexible form of training are three important elements. The internet development promotes diversified source of training information, the subject knowledge penetrate into each other, and the flexible handling is made under authoritative training team. The systematic theory and practical experience sharing can help to realize advanced early children education and then promote the development of rural kindergarten job-transfer teachers in Shaanxi province under the kindergarten backbone teachers' discussion on education experience.

\section{To motivate job-transfer teachers' initiative after taking the work}

The rural kindergarten job-transfer teachers in Shaanxi province shall obtain better external development environment and effective motivation to continuously dig their potential so that it is able to let kindergarten retain more excellent talents and motivate job-transfer teachers' work enthusiasm. Firstly, it is required to let job-transfer teachers clearly know the essence of pre-school education so as to enhance their sense of professional identity and specify their development planning. Secondly, it is required to carry out periodical education and reflection to improve their enthusiasm in children's recreational and sports activities, and let them actively learn more professional skills, including dance, fine arts, and electronic organ, etc. Through continuous guidance and encouragement, the job-transfer teachers' internal driving force can be truly activated.

\section{To change job-transfer teachers' concepts and exert their subjective initiative}

The early children education mainly faces toward the children at an age of 4 or 5 , and the children teachers shall take more responsibility to care those flowers of our motherland. The rural kindergarten job-transfer teachers in Shaanxi province shall be fully aware of long-term education development and special educated group; on the basis of following the laws of children's somatopsychic development, the teachers shall change their concepts and truly accept children's purity and beauty so as to make preparation for smooth job-transfer. Certainly, the teachers will meet different development difficulties at each stage, and they can smoothly pull through the difficulties only after they find the solutions most suitable for themselves. If they merely show fear or have imbalanced attitude, it is very likely that their future development is hindered. Therefore, as for rural kindergarten job-transfer teachers in Shaanxi province, it is of important significance for them to exert their subjective initiative. Firstly, the job-transfer teachers shall lay down inner burden, and seek advice of teaching and life from other colleagues with an open mind. Secondly, the job-transfer teachers shall strive to summarize experience in teaching practice, update education theory according to time development, and make full use of advanced teaching technology to improve their professional accomplishments so as to lay a good foundation for them to be capable of work posts.

To meet job-transfer teachers' demand and carry out humanized management as much as possible

No matter what industry people engage in, they will have multiple inadaptation while they face job-transfer pressure, and the psychological demand and capacity demand are very obvious within short term. The specific representation is the reconstruction of self-confidence after job transfer, and this process is mainly reflected at understanding demand and growth demand, thus the surrounding colleagues shall give certain understanding, and the job-transfer teachers shall also carefully understand the essence of early children education post so that they can prepare well to continue to meet challenges. After the rural kindergarten job-transfer teachers in Shaanxi province transfers their job, the common behaviors are that their mastery of teaching features is out of control, and they lack of certain deep knowledge of view of children education; under urgent demand of competency, the psychological problems may happen. Therefore, it is required to timely meet job-transfer teachers' capacity demand, establish the sense of competence, and reduce the sense of frustration, which can help the benign development of rural kindergartens in Shaanxi province. The kindergarten leaders shall have the awareness to help job-transfer teachers to establish a good interpersonal circle, and the 
establishment of sense of belonging is also an important aspect which meets the demand of rural kindergarten job-transfer teachers in Shaanxi province.

To combine job-transfer training and kindergarten training, and improve job-transfer teachers' professional ability

To carry out targeted and effective kindergarten training in transition period are two important measures of improving job-transfer teachers' professional ability. In realistic life, the job-transfer training just becomes a mere formality in most places, which causes serious barrier on job-transfer teachers' competency level; the teachers' work is passive and the teaching quality decreases. Therefore, in the rural kindergarten job-transfer work in Shaanxi province, the local education department shall make overall plans and take all factors into consideration, and participate in kindergarten training activities while providing teachers with more choices. In the job-transfer training, it is required to place teachers' ethics at the first place, integrate existing resource to set systematic training items, perfect kindergarten supervision system, and innovate training and teaching methods to realize the expected objective through investigation and analysis on a series of cases. The centralized training shall coordinate with kindergarten training; the children developmental psychology, pedagogy, sanitation and child care and other theoretical knowledge are main theoretical teaching content, and the handcraft, fine arts, music, and dance are main practical teaching content. Through creating different teaching environment and game content, the job-transfer teachers correctly participate in and experience daily kindergarten teaching under the predecessors' guidance. Generally speaking, the green hands, qualified personnel, backbone personnel, and experts are four stages of teacher's occupational development, and the job-transfer teachers are under the transition stage from green hands to qualified teachers; it is certain that the original knowledge structure will cause influence on teaching process, thus how to integrate their teaching experience to handle children teaching classroom events and make changes from passive state to active state is a long process. In order to help rural kindergarten job-transfer teachers in Shaanxi province to further adapt to new change in new post, the new ability model is established based on original knowledge structure; before forming a mature cognition on children education, the job-transfer teachers shall learn work experience from their colleagues, and the managers shall change their traditional concepts and provide skill guidance.

\section{To establish talent files of job-transfer teachers based on age}

The age is an important ruler used to set job-transfer work; according to statistics of relevant data, the teachers with an age above 40 have a weaker ability to adapt to new working environment and a weaker working ability than the teachers with an age below 40. Therefore, the rural kindergarten job-transfer teachers in Shaanxi province can transfer them to logistics department to serve as a registry officer or child-care worker; as for teachers with an age below 35 who voluntarily apply for job transfer, they can go to children normal colleges to participate in professional training and then officially take the post after they are qualified through assessment. Besides, it is required to carry out management on the talent files special for rural kindergarten job-transfer teachers in Shaanxi province, and combine with teachers' personal interests and strong points to carry out post matching to further enhance the survival ability and competence level of rural kindergarten job-transfer teachers in Shaanxi province. For example, the teachers with strong points in fine arts and music can be arranged to engage in the work of skill-oriented subjects and the teachers with strong points in writing can be arranged to work in propaganda department. Then, through combination with job-transfer strategies, it is able to finally realize the application effect of two-way selection and scientific mobility of rural kindergarten faculty in Shaanxi province.

\section{Conclusion}

In conclusion, through exploration on survival status and competency level of rural kindergarten job-transfer teachers in Shaanxi province, it can be found that the problems faced by job-transfer teachers in early children education work are specific and temporary; some problems can be solved 
by job-transfer teachers by use of their own ability, and some problems need to be solved under the joint efforts of managers and teachers.

\section{Acknowledgments}

This paper is a scientific research project of Education Department of Shaanxi Provincial Government (project name: Research on Survival Status and Competency Level of Rural Kindergarten Job-transfer Teachers in Shaanxi Province; project No.: 2013JK0416) and also a project of Shaanxi provincial education science "twelfth five-year" planning (project name: Action Research on Competency Level of Rural Kindergarten Job-transfer Teachers in Shaanxi Province; project No.: SGH13367).

\section{References}

[1] Cui Xinling, Peng Hailei. Occupational Adaptive Status of Rural Kindergarten Job-transfer Teachers and Influence Factors - Take Shaanxi Province as an Example, Early Education (Teaching and Scientific Research Version), 2013 (06): 44-47.

[2] Zhang Jili: Experts' Guidance. Ladder for Kindergarten Teachers' Professional Growth at Mature Stage, Early Childhood Education (Educational Sciences), 2014 (12): 31-33.

[3] Yang Cuimei. Problems Existing in Teachers' Job Transfer from Primary Schools to Kindergartens and Countermeasures - Take One Town in Xi'an City of Shaanxi Province as an Example, Early Childhood Education (Educational Sciences), 2012 (1): 43-46.

[4] Zhang Shiwen. Guidance on Rural Kindergarten Job-transfer Teachers, Preschool Education (Early Childhood Education Version), 2013 (5): 16-17.

[5] Liu Chunqiong. Reasons, Problems and Countermeasures for Primary School Teachers' Job Transfer to Kindergarten, Studies In Preschool Education, 2011 (10): 64-66. 